\title{
Photocurable Epoxy Acrylate Coatings Preparation by Dual Cationic and Radical Photocrosslinking
}

\author{
Paulina Bednarczyk*, Karolina Mozelewska, Małgorzata Nowak and Zbigniew Czech (D)
}

Department of Chemical Organic Technology and Polymeric Materials, Faculty of Chemical Technology and Engineering, West Pomeranian University of Technology in Szczecin, Piastów Ave. 42, 71-065 Szczecin, Poland; karolina_mozelewska@zut.edu.pl (K.M.); gosia.nowak.zut@gmail.com (M.N.); psa_czech@wp.pl (Z.C.)

* Correspondence: bednarczyk.pb@gmail.com or paulina.bednarczyk@zut.edu.pl

Citation: Bednarczyk, P.;

Mozelewska, K.; Nowak, M.; Czech,

Z. Photocurable Epoxy Acrylate

Coatings Preparation by Dual

Cationic and Radical

Photocrosslinking. Materials 2021, 14,

4150. https://doi.org/10.3390/

ma14154150

Academic Editor: Béla Iván

Received: 7 July 2021

Accepted: 24 July 2021

Published: 26 July 2021

Publisher's Note: MDPI stays neutral with regard to jurisdictional claims in published maps and institutional affiliations.
Abstract: In this work, epoxy acrylate resin (EA) based on the industrial-grade bisphenol A-based epoxy resin (Ep6) and acrylic acid (AA) has been synthesized in order to develop hybrid resin comprising both epoxide group and reactive, terminal unsaturation. Obtained epoxy acrylate prepolymer was employed to formulate photocurable coating compositions containing, besides the EA binder, also cationic or radical photoinitiators. Hence, when cationic photoinitiators were applied, polyether-type polymer chains with pending acrylate groups were formed. In the case of free radical polymerization, epoxy acrylates certainly formed a polyacrylate backbone with pending epoxy groups. Owing to the presence of both epoxy and double carbon-carbon pendant groups, the reaction product exhibits photocrosslinking via two distinct mechanisms: (i) cationic ring-opening polymerization and (ii) free radical polymerization. Therefore, photopolymerization behavior of synthetized hybrid resin with various photoinitiators was determined via photo-differential scanning calorimetry (photo-DSC) and real-time infrared spectroscopy (RT-IR) methods, and properties of cured coatings were investigated. The performance of the following type of photoinitiators was tested in the cationic photopolymerization: diaryliodonium cations or triarylsulfonium cations, and the following type of photoinitiators were used to induce free radical photopolymerization: $\alpha$-hydroxyketones, acylphosphine oxides, and their mixtures. Lastly, the basic physicomechanical properties of cured coatings, such as tack-free time, hardness, adhesion, gloss, and yellowness index, were evaluated. Some structural factors and parameters of cationic and radical photoinitiators and photopolymerization mechanisms affecting the epoxy acrylate hybrid coatings performance are discussed.

Keywords: epoxy acrylates; coatings; photopolymerization; photoinitiators

\section{Introduction}

The polymerization of multifunctional monomers or oligomers by UV curing has become a widely used technology that has found many industrial applications due to its unique advantages. The coating industry is the most important application of UV curing technology and used to protect the surface of materials with quick-drying varnishes or printing inks. Other uses include manufacturing solder mask, stereolithography, and microelectronic photoresists. In addition, quick-setting adhesives, coatings, sealants, and the production of composite materials are just some of the many applications of photopolymerization [1-3]. So many applications result from the high speed of curing by UV radiation and the high efficiency of the process. This solution also exhibits a few other advantages; it is environmentally friendly with the possibility of adjusting parameters (from brittle to very flexible films), curing at ambient temperature, and adjusting the properties of the final product to the needs [4,5]. Compared to traditional coatings (e.g., solvent-based coatings), UV-curable coatings provide energy savings and low volatile organic compounds [6-8]. This is believed to be the most effective method to rapidly convert a solvent-free liquid 
resin into a solid polymer at ambient temperature. Under intense lighting, the cross-linking polymerization of the resins is intense, sometimes within a fraction of a second, creating a dense three-dimensional polymer network that exhibits excellent resistance to organic solvents, chemicals, and heat $[4,6]$.

In the photopolymerization process, the type of monomer and photoinitiator are of great importance, because the compositions can be polymerized using a free radical or cationic photopolymerization mechanism [7,8]. Currently, free radical photopolymerization is used most often due to the large assortment and low cost of free radical monomers, photoinitiators, and additives to set the final properties, with the possibility of combining them into products with different properties. In turn, the disadvantage of these systems is the inhibition of free radical polymerization by oxygen $[9,10]$. Cationic photopolymerization is an alternative polymerization method in the production of cured coatings. The cationic process is not inhibited by oxygen. Compared to free-radical photopolymerization, it does not stop immediately after the radiation is turned off, but occurs from darkness, sometimes slower, which is referred to as dark curing [11-13]. These types of features are important when uneven and complex-shaped coatings are cured. In addition, cationic photopolymerization only leads to low shrinkage (e.g., for epoxy coatings around 5\%). In turn, many hydrogen bonds are formed during the process, which leads to an increase in adhesion between the material and the coating [14]. Curing coatings with cationic photopolymerization is often used for monomers that cannot be photopolymerized in a free radical manner, e.g., vinyl ethers and epoxides [15,16].

To overcome the limitations of acrylates and epoxides, a product can be synthesized based on acrylate and epoxy monomers. In this case, the monomers can polymerize by various mechanisms, and the resulting products combine the properties of both acrylates and epoxides, making them suitable for various applications [17]. Epoxy acrylates are characterized by flexibility, hardness, thermal resistance, and non-yellowing. In their case, the epoxy backbone increases strength and flexibility during curing, while carbon-carbon and ether bonds improve chemical resistance. Moreover, due to their low cost, excellent chemical and corrosion resistance, and favorable mechanical properties and good processability, they are used in many areas of the industry [18,19]. Poor exterior durability and high viscosity are the main disadvantages associated with these materials. The use of UV and thermally curable epoxy acrylate prepolymers has increased in recent years. They are used as varnishes, wood coatings, or lithographic paints. They are popular in other areas as well: vacuum metalizing base coatings, video disc coatings, and adhesive laminates [20-22].

In this contribution, the modification of epoxy resin with methacrylic acid, allowing the obtainment of a hybrid polymer containing both epoxy and acrylic groups, has been reported. Subsequently, photoreactive coating compositions were prepared from the obtained epoxy acrylate and cured using UV radiation. The samples were tested for the kinetics of the process and the properties of the cured coatings. Both the cationic and free radical photopolymerization of synthetized EA have been investigated by the photo-DSC and RT-IR method, and the suitability of various photoinitiators for photopolymerization of the hybrid systems using a UV lamp is evaluated.

\section{Materials and Methods}

\subsection{Materials}

The industrial-grade bisphenol A-based epoxy resins were purchased from "OrganikaSarzyna" S.A., Nowa Sarzyna, Poland. The following epoxy resins were used: Epidian $6^{\circledR}$ (Ep6), with epoxide number of $0.51-0.54 \mathrm{~mol} / 100 \mathrm{~g}$ and viscosity ranging from 10,000 to $15,000 \mathrm{mPa} \cdot \mathrm{s}$ at $25^{\circ} \mathrm{C}$, and acrylic acid (AA), stabilized, with the purity of $99.5 \%$, supplied by Acros Organics, Geel, Belgium. Triphenylphosphine $\left(\mathrm{PPh}_{3}\right)$, Apollo Scientific, Bredbury, UK, was used as a catalyst in the reaction between Ep6 and AA, while hydroquinone (HQ, Acros Organics, Geel, Belgium) was used as a polymerization inhibitor. All chemicals were employed as received. 
The following titration reagents and indicators were used: glacial acetic acid, toluene, potassium hydroxide standard solution $0.1 \mathrm{M}$ in ethanol $(\mathrm{KOH})$, and crystal violet purchased from Chempur (Piekary Slaskie, Poland), chloroform form P.P.H. Stanlab (Lublin, Poland), ethyl alcohol from Avantor (Gliwice, Poland), tetraethylammonium bromide provided by Acros Organics (Geel, Belgium), perchloric acid standard solution $0.1 \mathrm{M}$ in glacial acetic acid supplied by Fischer Chemicals (Zurich, Switzerland), and Phenolophtalein $1 \%$ in ethyl alcohol solution from Eurochem BGD (Tarnów, Poland). All chemicals were analytical grade and were used as received.

The diaryliodonium and triarylsulfonium cation-based photoinitiators were selected from the many cationic photoinitiators available. The following photoinitiators based on the diaryliodonium cation were used to induce cationic photopolymerization of hybrid resin: (4-methylphenyl)[4-(2-methylpropyl)phenyl]iodonium hexafluorophosphate (Irgacure 250) from BASF (Ludwigshafen, Germany), bis(dodecylphenyl)iodoniumhexaflouroantimonate in propylene carbonate (Deuteron 1240) and bis-((C10-C13)alkylphenyl)-iodoniumhexafluor oantimonate (Deuteron 1250) from Deuteron (Achim, Germany), (7-methoxy-4-methylcoum arin-3-yl)phenyliodonium hexafluoroantimonate (Sylanto 7M-S) and (7-methoxy-4-methylco umarin-3-yl)phenyliodonium hexafluorophosphate (Sylanto 7M-P) from Synthos S.A. (Oświęcim, Poland). The following photoinitiators were selected from the cationic photoinitiators based on the triarylsulfonium cation: mixture triarylsulfonium hexafluoroantimonate salts (Cyracure UV6976) and mixture triarylsulfonium hexafluorophosphate salts (Cyracure UV6992) from Dow (Frankfurt, Germany). Structures of the cationic photoinitiators are shown in Figures 1 and 2.<smiles>Cc1ccc([I+](P)c2ccc(CC(C)C)cc2)cc1</smiles>

Irgacure 250

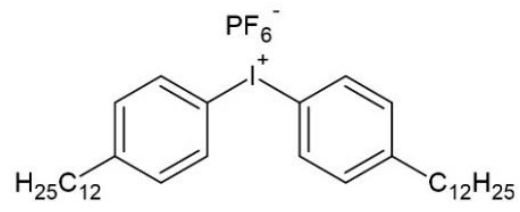

Deuteron UV1240<smiles>[R]C([R])c1ccc([I+]c2ccc(C([R])[R])cc2)cc1</smiles>

Deuteron UV1250

$$
\begin{gathered}
\mathrm{R}_{1}=\mathrm{CH}_{3}-\left(\mathrm{CH}_{2}\right)_{n} \\
\mathrm{R}_{2}=\mathrm{CH}_{3}-\left(\mathrm{CH}_{2}\right)_{\mathrm{m}} \\
\mathrm{n}+\mathrm{m}=7-10
\end{gathered}
$$<smiles>COc1ccc2c(C)c([I+]([S-])c3ccccc3)c(=O)oc2c1</smiles>

Sylanto 7M-S<smiles>COc1ccc2c(C)c([I+](P)c3ccccc3)c(=O)oc2c1</smiles>

Sylanto $7 \mathrm{M}-\mathrm{P}$

Figure 1. Structure of the cationic photoinitiators based on diaryliodonium cation.

As free radical photoinitiators for hybrid monomers, photoinitiators were used, which were divided into $\alpha$-hydroxyketones, acylphosphine oxides, and their mixtures. The following compounds were selected from the photoinitiators with the structure of $\alpha$ hydroxyketones: 1-hydroxycyclohexyl phenyl ketone (Omnirad 184), 2-hydroxy-1-\{4-[4(2-hydroxy-2-methyl-propionyl)-benzyl]-phenyl\}-2-methylpropan-1-one (Omnirad 127) and 1-[4-(2-hydroxyethoxyl)-phenyl]-2-hydroxy-methylpropanone (Omnirad 2959) from IGM Resigns (The Netherlands). The structures of the free-radical photoinitiators $\alpha-$ hydroxyketones are collected in Figure 3. The following were selected as acylphosphine oxides: 2,4,6-trimethylbenzoyl-diphenyl phosphine oxide (Lucirin TPO), (ethyl-2,4,6trimethylbenzoylphenylphosphinate) (Lucirin TPO-L) from BASF (Germany) and bis(2,4,6- 
trimethylbenzoyl)-phenylphosphineoxide (Omnirad 819) from IGM Resigns (Netherlands). The structures of the free-radical photoinitiators-acylphosphine oxides are collected in Figure 4. The following were selected as mixtures of photoinitiators: a blend of 2-hydroxy2-methylpropiophenone phenyl bis(2,4,6-trimethylbenzoyl)-phosphine oxide and ethyl phenyl(2,4,6-trimethylbenzoyl) phosphinate (Omnirad 2022), a blend of ethyl phenyl(2,4,6trimethylbenzoyl) phosphinate and phenyl bis(2,4,6-trimethylbenzoyl)-phosphine oxide (Omnirad 2100) and a blend of 2, 4, 6-trimethylbenzoyl-diphenyl-phosphine oxide and 2-hydroxy-2-methyl-1-phenylpropanone (Omnirad 4265). All photoinitiators mixtures used were from IGM Resigns (Netherlands). The structures of free radical photoinitiatorsmixtures are presented in Figure 5.<smiles>[Ni]=[Sb](Br)(c1ccccc1)c1ccccc1</smiles><smiles>O=[SH](c1ccccc1)(c1ccccc1)c1ccc(Sc2ccccc2)cc1</smiles>

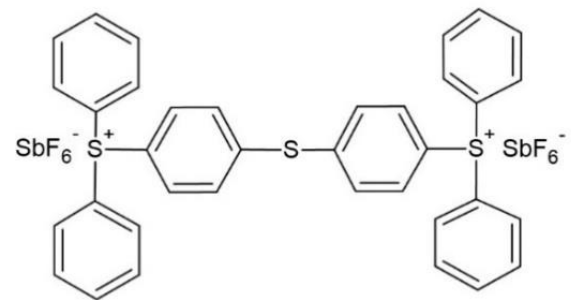

Cyracure UV6976<smiles>C[P+](c1ccccc1)(c1ccccc1)c1ccc(Sc2ccc([Sb](F)(=S)(c3ccccc3)c3ccccc3)cc2)cc1</smiles>

Cyracure UV6992

Figure 2. Structure of the cationic photoinitiators based on a triarylsulfonium cation.<smiles>CCCC(O)(CCC)C(=O)c1ccccc1</smiles>

Omnirad 184<smiles>CC(C)(O)C(=O)c1ccc(Cc2ccc(C(=O)C(C)(C)O)cc2)cc1</smiles>

Omnirad 127<smiles>CC(C)(O)C(=O)c1ccc(OCCO)cc1</smiles>

Omnirad 2959

Figure 3. Structure of the free-radical photoinitiators $\alpha$-hydroxyketones.<smiles>Cc1cc(C)c(C(=O)P(=O)(c2ccccc2)c2ccccc2)c(C)c1</smiles>

Lucirin TPO<smiles>CCOP(=O)(C(=O)c1c(C)cc(C)cc1C)c1ccccc1</smiles>

Lucirin TPO-L<smiles>Cc1cc(C)c(C(=O)P(=O)(C(=O)c2c(C)cc(C)cc2C)c2ccccc2)c(C)c1</smiles>

Omnirad 819

Figure 4. Structure of the free-radical photoinitiators-acylphosphine oxides. 
<smiles>[111InH]</smiles><smiles></smiles>

Omnirad 2022<smiles>Cc1cc(C)c(C(=O)P(=O)(C(=O)c2c(C)cc(C)cc2C)c2ccccc2)c(C)c1</smiles><smiles>CCOP(=O)(C(=O)c1c(C)cc(C)cc1C)c1ccccc1</smiles>

Omnirad 2100<smiles>Cc1cc(C)c(C(=O)P(=O)(c2ccccc2)c2ccccc2)c(C)c1</smiles><smiles>CC(C)(O)C(=O)c1ccccc1</smiles><smiles>CC(C)(O)C(=O)c1ccccc1</smiles>

Omnirad 4265

Figure 5. Structure of the free-radical photoinitiators-mixtures.

It has long been known that the effectiveness of a photoinitiator depends on matching the absorption spectrum with the emission spectrum of the light source. It is important that the maximum of the absorption peak is in the range of the lapa emission. Table 1 shows the maximum absorption peaks of the tested photoinitiators.

\subsection{Synthesis of Epoxy-Scrylate Pre-Polymer}

Epoxy acrylates (EAs) were obtained by the addition of acrylic acid to epoxy resin. The synthesis was carried out in a $250 \mathrm{~mL}$ three-neck glass reactor (equipped with a thermometer, a condenser, a nitrogen inlet, and a mechanical stirrer), into which bisphenol A type epoxy resin (Epidian 6) was introduced. Then, hydroquinone $(0.0075 \mathrm{wt} . \%$ based on total batch weight) was transferred into the reactor as a radical scavenger at room temperature. Lastly, acrylic acid ( $0.5 \mathrm{~mol}$ relative to resin epoxy value) and catalysttriphenylphosphine in the amount of $0.8 \mathrm{wt}$.\% (relative to the mass of AA) were added. The reaction mixture was heated to $70{ }^{\circ} \mathrm{C}$ with vigorous stirring (120 RPM) using an oil bath. Once the homogeneous mixture was obtained, the temperature was raised to $90^{\circ} \mathrm{C}$, and the reaction was carried out for $4 \mathrm{~h}$ in a nitrogen atmosphere, with stirring. At room temperature, the as-prepared EA appears as colorless, transparent, viscous liquids. The reaction product is presented in Figure 6. The epoxy acrylate pre-polymer obtained 
and analyzed in the present work will be denoted as EA-FI, depending on the type of applied photoinitiator.

Table 1. The maximum absorption peaks of the photoinitiators used.

\begin{tabular}{|c|c|c|c|c|}
\hline \multicolumn{4}{|c|}{ Photoinitiator } & \multirow{2}{*}{ Absorption Peaks (nm) } \\
\hline & Type & Name & Abbreviation & \\
\hline \multirow{7}{*}{ Cationic } & \multirow{5}{*}{ diaryliodonium cation } & Irgacure 250 & Ir250 & 242 \\
\hline & & Deuteron UV1240 & D1240 & 240 \\
\hline & & Deuteron UV1250 & D1250 & 240 \\
\hline & & Sylanto 7M-S & $7 \mathrm{MS}$ & 350 \\
\hline & & Sylanto 7M-P & $7 \mathrm{MP}$ & 350 \\
\hline & \multirow{2}{*}{ triarylsulfonium cation } & Cyracure UV6976 & C76 & 240,300 \\
\hline & & Cyracure UV6992 & C92 & 240,300 \\
\hline \multirow{9}{*}{ Radical } & \multirow{3}{*}{$\alpha$-hydroxyketones } & Omnirad 184 & O184 & $246,280,333$ \\
\hline & & Omnirad 127 & $\mathrm{O} 127$ & 200,260 \\
\hline & & Omnirad 2959 & O2959 & 200,280 \\
\hline & \multirow{3}{*}{ acylphosphine oxides } & Lucirin TPO & TPO & $295,368,380,393$ \\
\hline & & Lucirin TPO-L & TPOL & 300,380 \\
\hline & & Omnirad 819 & O819 & 295,370 \\
\hline & \multirow{3}{*}{ mixtures } & Omnirad 2022 & $\mathrm{O} 2022$ & $246,282,370$ \\
\hline & & Omnirad 4265 & $\mathrm{O} 4265$ & 275,370 \\
\hline & & Omnirad 2100 & $\mathrm{O} 2100$ & $240,272,380$ \\
\hline
\end{tabular}<smiles>C=CC(=O)OCC(O)COc1ccc(C(C)(C)c2ccc(OCC(O)COc3ccc(C(C)(C)c4ccc(C)cc4)cc3)cc2)cc1</smiles>

Figure 6. Structure of epoxy acrylate prepolymer.

\subsection{Characterization Methods}

The infrared spectra acquired with a Thermo Nicolet 380 FT-IR spectrometer. Sixteen scans were averaged for each sample in the range of $4000-400 \mathrm{~cm}^{-1}$ at room temperature. The non-volatile-matter content (NV) was evaluated thermogravimetrically, using moisture analyzer MAX 60/NP (Radwag, Poland), according to the ISO 3251:2019 standard. Partial acid values (PAVs) were determined by colorimetric titration according to EN ISO 2114:2000 standard. Epoxy equivalent (EE) was determined by means of colorimetric titration, according to the EN ISO 3001:1999 standard. The viscosity tests were carried out using a cone-plate viscometer LAMY RM-100 plus CP 2000. The test methods were described in detail in our previous article on epoxy acrylate prepolymers [23]. The molecular weight studies were performed in tetrahydrofurane with a liquid chromatograph LaChrom system, RI Detector L-7490 and LaChrom UV Detector L-7400 from Merck-Hitachi, equipped with a PLgel 106 Å column from Hewlett-Packard.

\subsection{Preparation of Coating Compositions and Cured Films}

The coating compositions have been formulated using epoxy resin or synthesized epoxy acrylate and $3 \mathrm{wt} . \%$ of photoinitiator (cationic or radical). The components were stirred together under dark conditions until a homogeneous mixture was obtained. Subsequently, the curing solution was applied to the glass substrates by means of a gap applicator $(120 \mu \mathrm{m})$. The polymeric film was cured under a light source (UV lamp, Aktiprint-mini 18-2, type: UN50029, Technigraf $\mathrm{GmbH}$ ) at room temperature and irradiated under UV light with an intensity of $200 \mathrm{~mW} / \mathrm{cm}^{2}$ to dryness. 


\subsection{Characteristics of the Photopolymerization Process and Properties of Cured Coatings}

The UV-curing process of epoxy or epoxy acrylate varnishes was isothermally monitored $\left(25^{\circ} \mathrm{C}\right)$ for $15 \mathrm{~min}$ by means of photo-DSC apparatus (Q100, TA Instruments, New Castle, DE, USA) equipped with UV light emitter Omnicure S2000 (Excelitas Technologies, Waltham, MA, USA). The spectrum range of the lamp is 320-500 $\mathrm{nm}$. The OmniCure S2000 is equipped with a 200-W UV lamp. This allows the generation of UV light with a power of $200 \mathrm{~mW} / \mathrm{cm}^{2}$. A polymerization solution was composed of epoxy resin (Ep) or epoxy acrylate (EA) prepolymer and $3 \mathrm{wt} . \%$ of photoinitiator.

Fourier transform infrared spectra (FT-IR) were obtained on a Nicolet iS5 instrument. The resolution is $4 \mathrm{~cm}^{-1}$ and the scanning range is $400-4000 \mathrm{~cm}^{-1}$. The recording interval of the spectrum was $10 \mathrm{~s}$. Series real-time IR (RT-IR) was used to determine the conversion of epoxide groups or acrylic double bonds. More importantly, this spectroscopic technique permits in situ monitoring of the chemical processes via mimicking the disappearance of the characteristic bands of the reactive monomer subjected to UV exposure [24]. The mixture of Ep or EA and an initiator was placed in a mold made from glass slides and spacers of $15 \mathrm{~mm}$ in diameter and 1.2 in thickness. The samples were placed in the compartment of a Fourier transform infrared spectrometer and were simultaneously exposed to a UV radiation source (mercury UV lamp, $36 \mathrm{~W}, 280-400 \mathrm{~nm}, 10 \mathrm{~mW} / \mathrm{cm}^{2}$ ) and an IR analyzing light beam. The absorbance change of the epoxide group $(\mathrm{C}-\mathrm{O})$ and acrylate double bond $(\mathrm{C}=\mathrm{C})$ peak area was correlated to the extent of polymerization. The degree of conversion (DC) can be expressed by the following relations: $\mathrm{DC}(\%)=(\mathrm{A} 0-\mathrm{At}) \cdot 100 / \mathrm{A} 0$, where $\mathrm{A} 0$ is the initial peak area before irradiation and At is the peak area at time $t$. The photopolymerization rate $(\mathrm{Rp})$ was calculated by the following relations: $\mathrm{Rp}=\mathrm{dDC} / \mathrm{dt}$, where $\mathrm{t}$ is the time of irradiation [25].

The following tests were performed in order to evaluate the mechanical properties of cured coatings: tack-free time, pendulum hardness test, adhesion, gloss, and yellowness index. Tack-free time was measured as a surface cure time according to ISO 9117. It is the time at which the coating is deemed to be properly adhered to and achieves the final technical parameters. The hardness of coatings was tested using Persoz pendulum hardness on the glass substrate (TQC Sheen, Capelle an den Ijssel, The Netherlands) according to ISO 1522 standard. According to the PN-EN ISO 2409 standard, the adhesion to the glass substrate was determined (cross-cut method; BYK, Wesel, Germany). Gloss was measured by spectrometer GLS (SADT Development Technology Co. Ltd., Beijing, China) according to ASTM D523. The yellowness index is a number calculated from spectrophotometric data that describes the change in color of test samples. This parameter was measured according to ASTM E313 using precision colorimeter NH-145 (3NH Technology Co. Ltd., Shenzhen, China).

\section{Results}

\subsection{The Approach to the Development of the EA Prepolymer Synthesis Parameters}

The addition reaction of AA to the epoxy resin was carried out in order to obtain a hybrid resin containing both epoxy and acrylic groups in the molecule, which will be used in the further part of the research to monitor the course of cationic and radical photopolymerization with the use of various photoinitiators. Herein, the process parameters were developed based on a literature survey [26-30] and several preliminary runs carried out at different reaction temperatures and catalyst doses. The progress of the reaction was monitored by FT-IR spectroscopy. In particular, the absorption bands corresponding to the vibrations of carboxyl and epoxy groups are of special interest to evaluate the extent of reactions in the investigated system. In fact, from Figure 7, it can be observed that in the EA prepolymer, the intensity of the IR absorption bands arising from $-\mathrm{C}-\mathrm{H}\left(3057 \mathrm{~cm}^{-1}\right), \mathrm{C}-\mathrm{O}$ $\left(914 \mathrm{~cm}^{-1}\right)$, and $\mathrm{C}-\mathrm{O}-\mathrm{C}\left(825 \mathrm{~cm}^{-1}\right)$ stretching vibrations of oxirane groups [31-33] decrease, thus confirming that the ring-opening of epoxy groups took place. Furthermore, one can note that the peak at $1695 \mathrm{~cm}^{-1}$ originating from the carbonyl stretching mode in AA [34,35] becomes less intense as a result of the reaction and finally indistinguishable. Meanwhile, 
an additional absorption peak corresponding to $\mathrm{C}=\mathrm{O}$ stretching vibrations develops at $1722 \mathrm{~cm}^{-1}$, thereby suggesting that new bonds occur due to the reaction of carboxyl groups of AA and epoxide groups of Ep6, i.e., ester bonds. This agrees with the previous studies reporting the shift of the $\mathrm{C}=\mathrm{O}$ band after the esterification reaction [36]. Lastly, the progress of ring-opening reactions between epoxide groups and $\mathrm{AA}$ is highlighted by an increase in the intensity of broadband occurring in the range of $3600-3200 \mathrm{~cm}^{-1}$, due to $-\mathrm{O}-\mathrm{H}$ groups evolution $[17,33,37]$ resulting from the epoxide ring-opening.
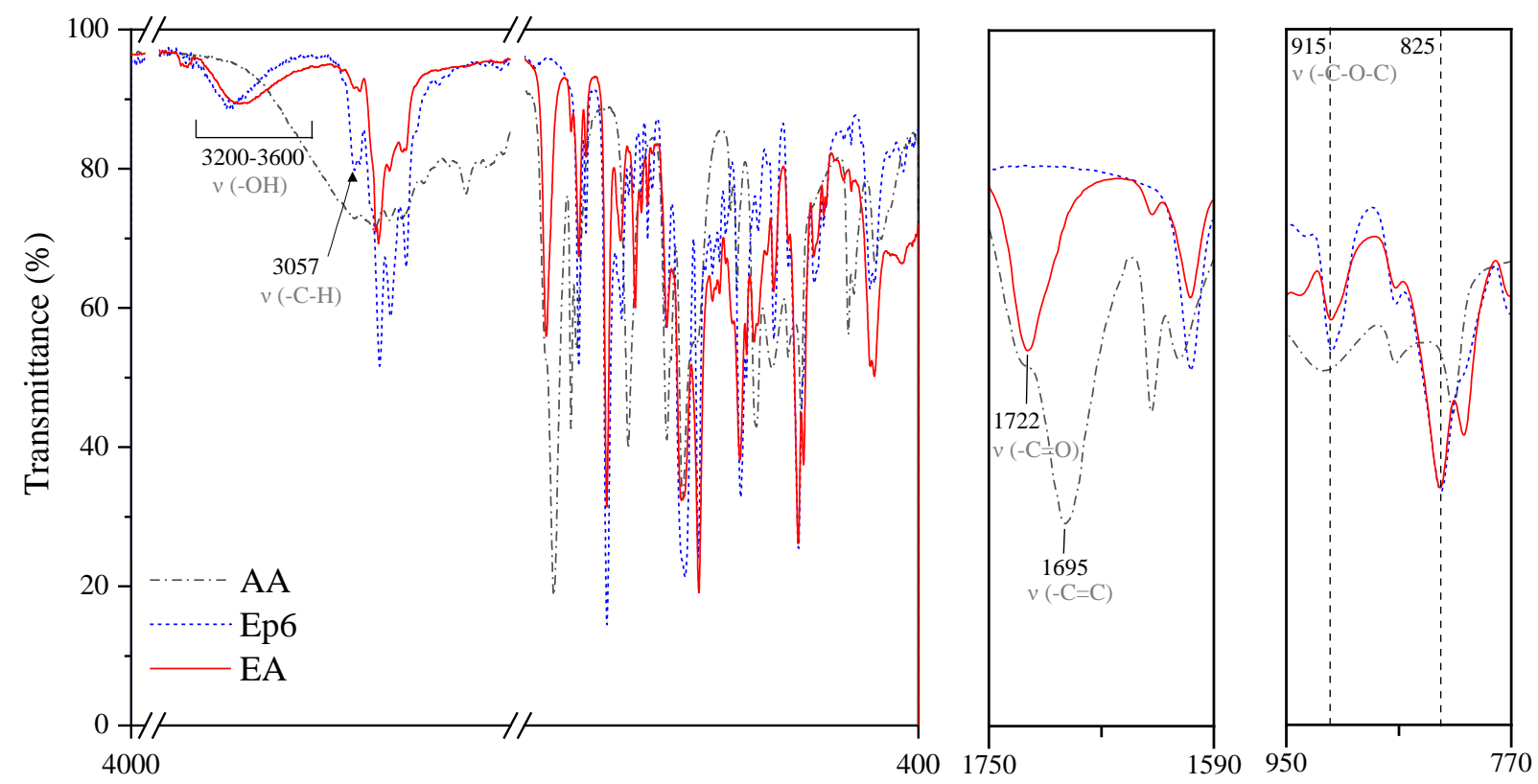

Wavenumber $(\mathrm{cm}-1)$

Figure 7. FT-IR spectra of epoxy resin, methacrylic acid, and EA prepolymer.

The product of reaction was also characterized for the non-volatile-matter content $(\mathrm{NV})$, partial acid value (PAVs), and epoxy equivalent (EE). Each of these can be regarded as a measure of reaction progress, which was referred to as the \% of reacted epoxide groups as well as \% of reacted AA and expressed as epoxy group conversion (EGC) and acrylic acid conversion (AAC). The synthesized EA prepolymer was $98.4 \%$ solids (NV). The viscosity of the resin increased and is 70 Pas. The acid number of the product (PAVs) was $2.9 \mathrm{mgKOH} / \mathrm{g}$, which indicates a conversion of acrylic acid in the amount of $97.9 \%$. In turn, the EE was 408 , so the conversion degree of epoxy groups was $49.6 \%$. The molecular weight of the obtained prepolymers was $977 \mathrm{~g} / \mathrm{mol}$.

\subsection{The Properties of Photocurable Coatings}

The kinetics of photopolymerization is useful in understanding the rate and degree of curing. It is well known that acrylates and methacrylates do not polymerize by a cationic polymerization mechanism, while epoxy monomers do not polymerize by free-radical means. Hence, when cationic photoinitiators were applied, polyether-type polymer chains with pending (meth)acrylate groups were formed. In the case of free-radical polymerization, epoxy (meth)acrylates certainly formed a polymethacrylate backbone with pending epoxy groups [23]. The process of photopolymerization of the obtained resin was tested by both photo differential scanning calorimetry (photo-DSC) and Fourier transform infrared spectroscopy for real-time process monitoring (RT-IR) methods. In a first approach, the photoinitiated cationic or radical polymerization of the obtained EA prepolymer was monitored by means of the photo-DSC method. Photo-DSC offers a simple method of characterizing the UV-curing kinetics for the photopolymerization of UV-cured materials. Therefore, the profiles for the heat of reaction versus time provided by photo-DSC can be 
used to describe the photoinduced reaction kinetics and evaluate the polymerization rate. In turn, through the RT-IR method, the curves of the conversion of epoxy or acrylate groups and photopolymerization rate (Rp) of EAs compositions with various photoinitiators were investigated. As expected, the progressive disappearance of the various IR bands characteristic of the epoxy or acrylate double bonds was observed. The extent of the epoxy groups' reactions was determined by the areas of the peak at $915 \mathrm{~cm}^{-1}$, which is due to $\mathrm{C}-\mathrm{O}$ stretching in the epoxy ring. Simultaneously, the extent of double bond reactions was determined by the peak areas of the double bond peak at $1635 \mathrm{~cm}^{-1}$.

Owing to the presence of both epoxy and double carbon-carbon bonds in the prepolymer chain, the resulting EAs are expected to exhibit curing behavior via two distinct mechanisms: (i) cationic ring-opening polymerization or (ii) free radical polymerization. First, the kinetics of cationic photopolymerization of the mixture of unmodified epoxy resin (E) and various cationic photoinitiators ( $3 \mathrm{wt} . \%$ ) were investigated. In the photo-DSC tests (irradiation conditions: $280-480 \mathrm{~nm}, 200 \mathrm{~mW} / \mathrm{cm}^{2}$ ), it was shown that triaryliodonium salts polymerize the fastest (C76 and C92; absorption characteristics: 240 and $300 \mathrm{~nm}$ ), despite their UV-C and UV-B absorption characteristics (Figure 8). They are followed by the diaryliodonium salts, i.e., (4-methylphenyl)[4-(2-methylpropyl)phenyl]iodonium hexafluorophosphate (Ir240), bis(dodecylphenyl) iodoniumhexaflouroantimonate (D40; absorption characteristics: 240 and $242 \mathrm{~nm})$, and bis-((C10-C13)alkylphenyl)-iodoniumhexafluoroantimonate (D50; absorption characteristics: 240 and $242 \mathrm{~nm}$ ), and the slowest were (7-methoxy-4methylcoumarin-3-yl)phenyliodonium hexafluoroantimonate (7MS) and (7-methoxy-4methylcoumarin-3-yl)phenyliodonium hexafluorophosphate (7MP; absorption characteristics: $350 \mathrm{~nm}$ ). Similar results were obtained by the RT-IR method (irradiation conditions: $280-400 \mathrm{~nm}, 10 \mathrm{~mW} / \mathrm{cm}^{2}$ ). Additionally, the conversion of epoxy groups was also investigated. As shown in Figure 9, the fastest polymerizing systems also had the highest degree of epoxy groups conversion. In the case of a relatively low polymerization rate, this type of relationship is often observed in literature reports.

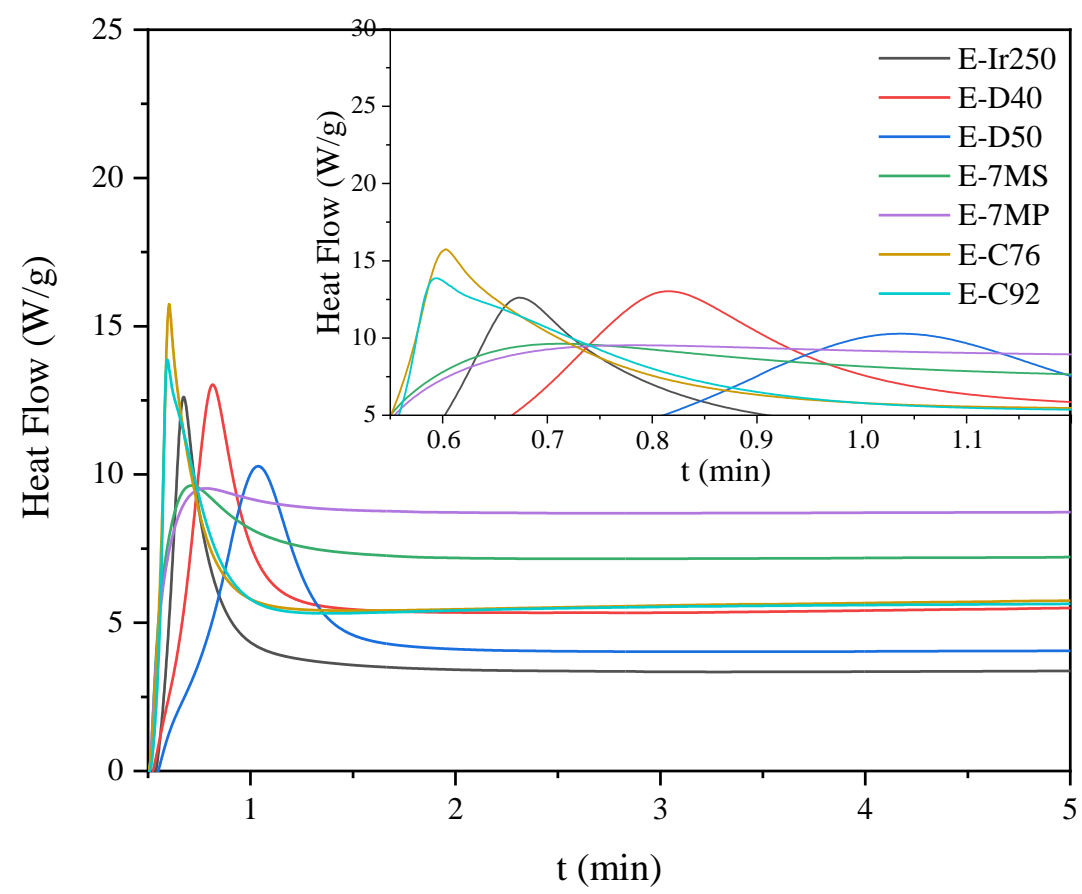

Figure 8. Photo-DSC exotherms for the photopolymerization of epoxy resin formulations with cationic photoinitiators.

Further, the research on systems from the synthesized hybrid epoxy acrylate resin is presented. It is worth emphasizing that owing to the presence of both epoxy and double carbon-carbon bonds in the polymer chain, the resulting EAs are expected to exhibit curing behavior via two distinct mechanisms: (i) cationic ring-opening polymerization and (ii) free 
radical polymerization. In the first approach, the photoinitiated cationic polymerization of the EA prepolymers was monitored by means of the photo-DSC method. The compositions used in the study included synthetized EA and a cationic photoinitiators ( $3 \mathrm{wt} . \%)$. Figure 10 shows the photocalorimetric exotherms for the photoinitiated cationic polymerization of obtained mixtures. The tested systems polymerize at a similar rate as unmodified systems, i.e., the fastest systems with triaryliodonium salts, then the diaryliodonium salts, and some diaryliodonium salts (7MS and 7MP). However, as shown in Figure 11, epoxy acrylate prepolymers are characterized by obtaining a lower conversion of epoxy groups compared to the unmodified resin and a lower photopolymerization rate. This effect is directly related to the lower content of epoxy groups in these systems due to partial reaction of these groups with acid at the stage of EAs' prepolymer synthesis.
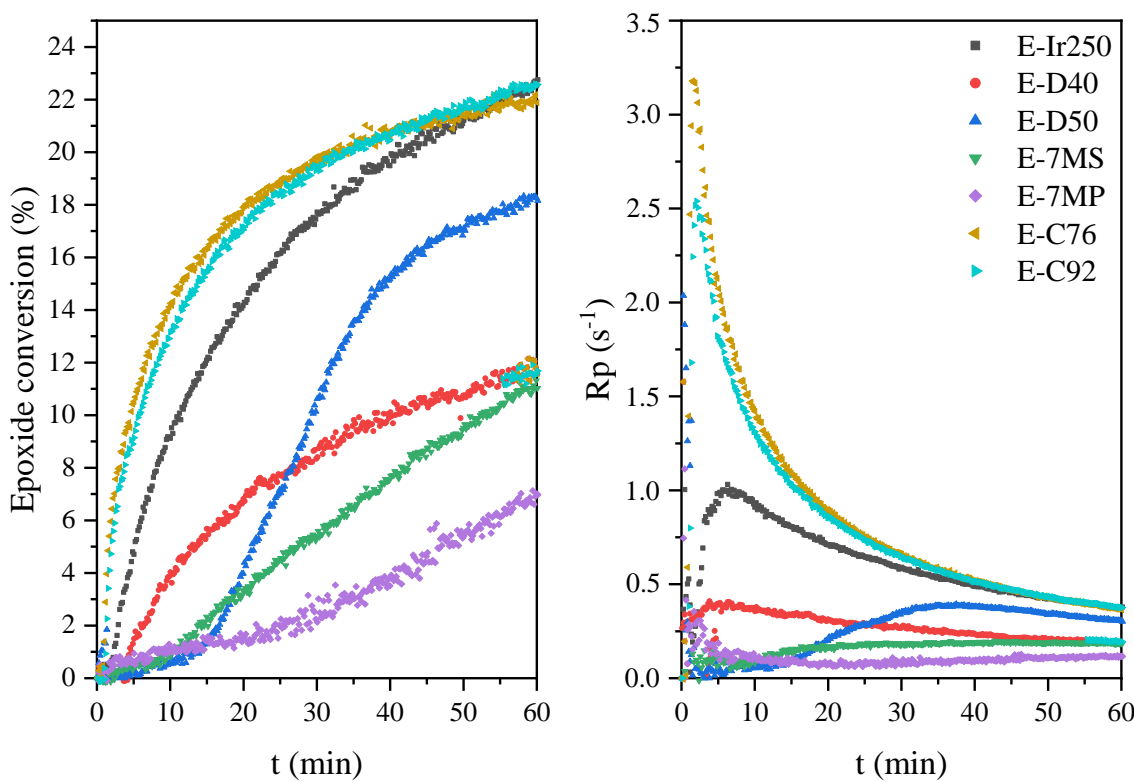

Figure 9. The epoxide conversion and photopolymerization rate curves of the epoxide resin formulations with cationic photoinitiators.

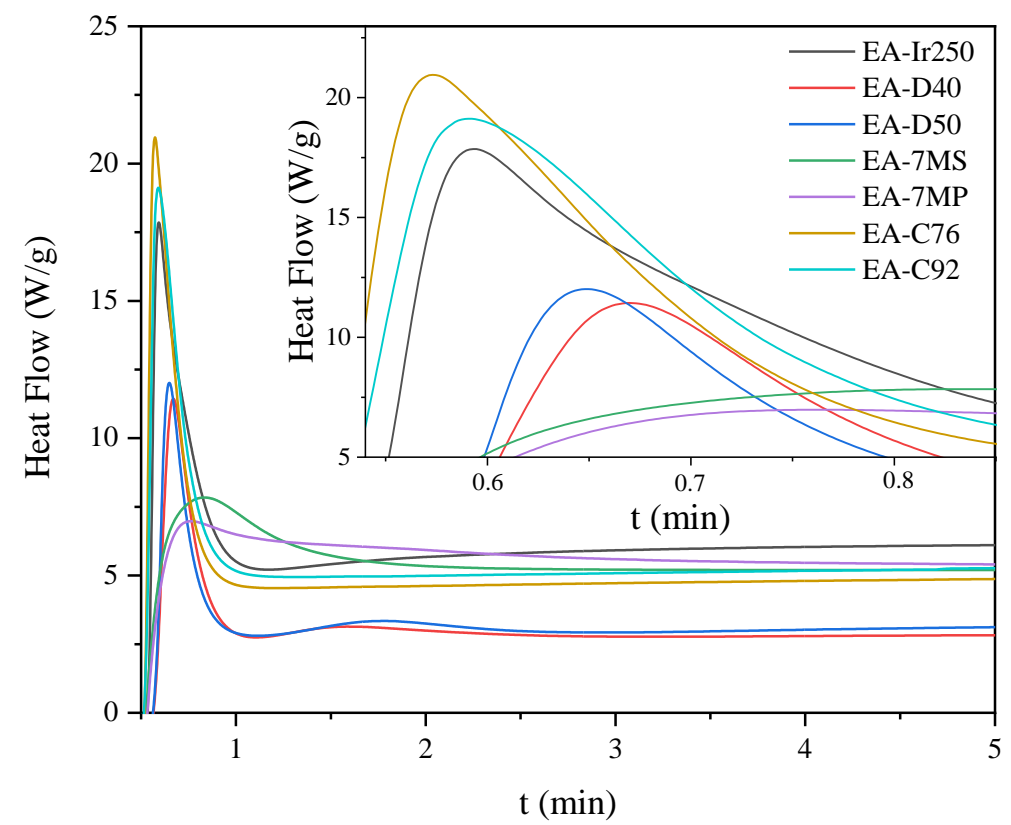

Figure 10. Photo-DSC exotherms for the photopolymerization of epoxy acrylate formulations with cationic photoinitiators. 

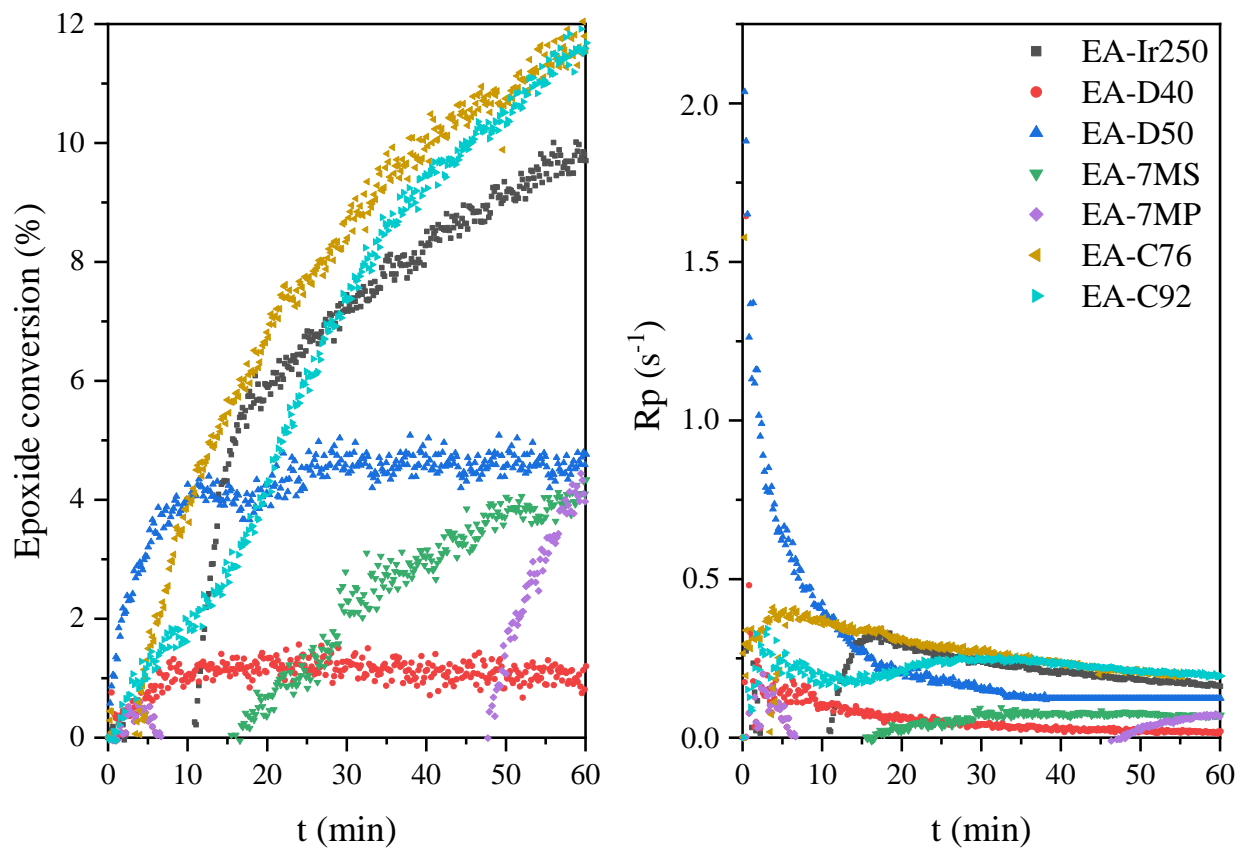

Figure 11. The epoxide conversion and photopolymerization rate curves of the epoxy acrylate formulations with cationic photoinitiators.

The next part concerns photoinitiated free radical polymerization of acrylate groups of EA chains, which was also monitored by both photo-DSC (Figure 12) and RT-IR (Figure 13) methods. In this case, the compositions used in the research included synthetized EA and a radical photoinitiators ( $3 \mathrm{wt} . \%$ ) belonging to $\alpha$-hydroxyketones, acylphosphine oxides, and mixtures of them. The photocalorimetric exotherms show the course of photoinitiated radical polymerization of the mixtures obtained. The investigated systems polymerize faster than the cationically polymerizing systems. The EA-O4265 system polymerized the fastest, and the slowest is EA-O2959. The highest conversion of acrylate groups was characterized by systems with photoinitiators in the form of mixtures of $\alpha$-hydroxyketones and acylphosphine oxides (EA-2022-60\% and EA-O4265-50\%), and these were much higher values compared to the conversion of epoxy groups in the cationic process. Thus, both the photopolymerization mechanism and the selection of an appropriate photoinitiator play an important role in the course of the process.

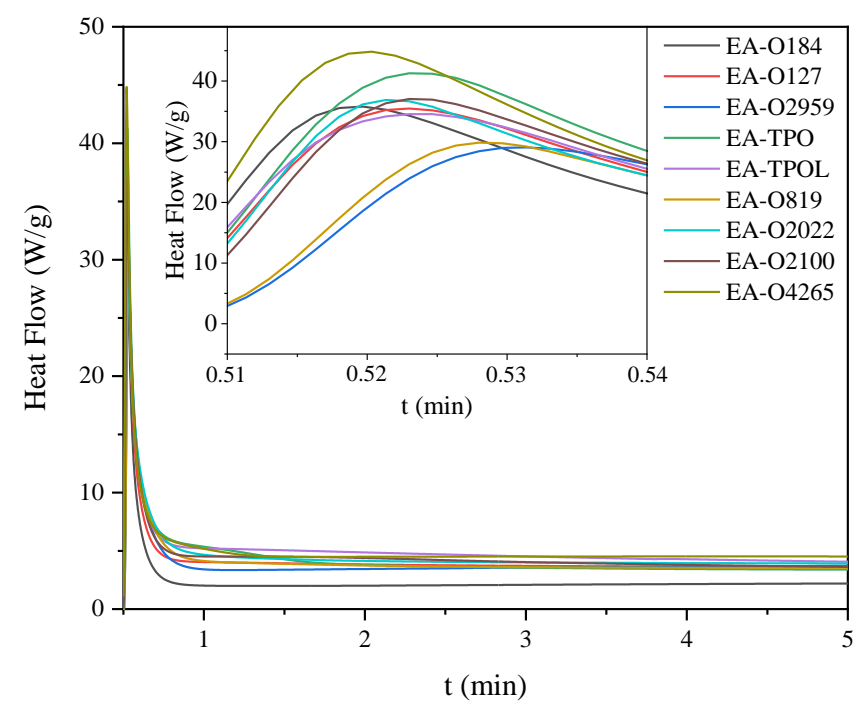

Figure 12. Photo-DSC exotherms for the photopolymerization of epoxy acrylate formulations with radical photoinitiators. 

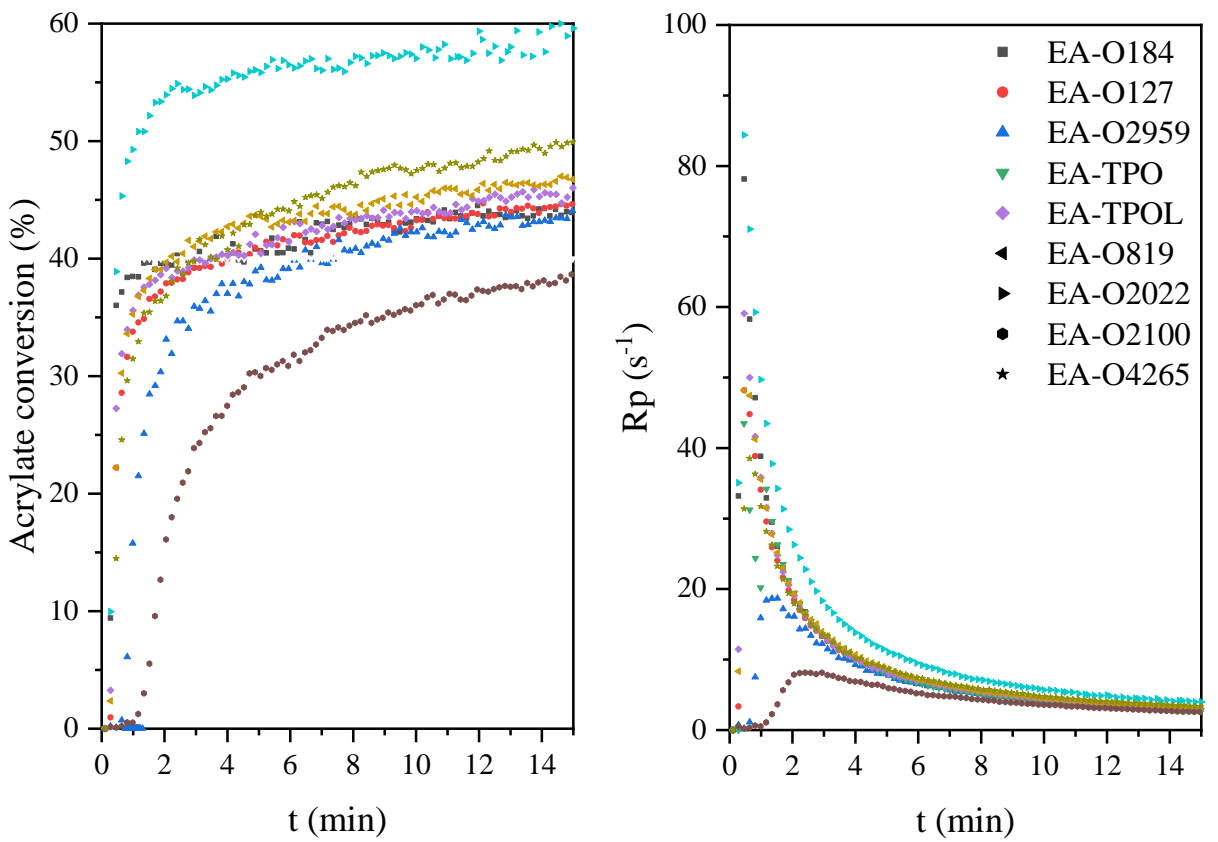

Figure 13. The acrylate conversion and photopolymerization rate curves of the epoxy acrylate formulations with radical photoinitiators.

In order to determine the effect of the type (cationic or radical) and the course of photopolymerization of systems with different photoinitiators, the basic properties of the cured films were investigated. The results are presented in Table 2. First, the results concerning the properties of coatings obtained from epoxy resin with cationic photoinitiators are presented, followed by the coatings obtained from epoxy acrylate resin with cationic or radical photoinitiators.

Table 2. Photopolymerization characteristics of the reaction mixtures and the basic properties of the cured coatings.

\begin{tabular}{|c|c|c|c|c|c|c|c|c|}
\hline Sample & $H_{\max }{ }^{(1)}(W / g)$ & $R_{p}^{\max (2)}\left(s^{-1}\right)$ & $X^{(3)}(\%)$ & Tack-Free Time (s) & Hardness (s) & Adhesion & Gloss (GU) & $\begin{array}{c}\text { Yellowness } \\
\text { Index }\end{array}$ \\
\hline E-Ir250 & 13 & 1.1 & 22 & 33 & 324 & 2.5 & 160 & 6.9 \\
\hline E-D40 & 13 & 0.4 & 12 & 39 & 266 & 3.5 & 180 & 5.4 \\
\hline E-D50 & 10 & 0.4 & 18 & 39 & 194 & 2.5 & 170 & 5.6 \\
\hline E-7MS & 9 & 0.2 & 11 & 30 & 118 & 3.5 & 115 & 21.6 \\
\hline E-7MP & 9 & 0.4 & 6 & 30 & 244 & 2 & 163 & 21.9 \\
\hline E-C76 & 16 & 3.2 & 21 & 39 & 297 & 0 & 188 & 7.6 \\
\hline E-C92 & 14 & 2.5 & 22 & 33 & 234 & 0 & 187 & 7.5 \\
\hline EA-Ir250 & 18 & 0.3 & 10 & 57 & 333 & 1 & 89 & 6.7 \\
\hline EA-D40 & 11 & 0.2 & 1 & 57 & 310 & 3 & 100 & 4.5 \\
\hline EA-D50 & 12 & 2.0 & 5 & 57 & 205 & 3 & 127 & 3.7 \\
\hline EA-7MS & 5 & 0.1 & 4 & 36 & 235 & 3 & 95 & 19.7 \\
\hline EA-7MP & 4 & 0.2 & 4 & 39 & 267 & 4 & 163 & 15.7 \\
\hline EA-C76 & 21 & 0.4 & 12 & 39 & 344 & 1 & 170 & 6.3 \\
\hline EA C92 & 19 & 0.3 & 12 & 39 & 312 & 1 & 170 & 7.3 \\
\hline EA-O184 & 36 & 78.2 & 44 & 3 & 101 & 4 & 43 & 7.1 \\
\hline EA-O127 & 35 & 48.2 & 44 & 3 & 95 & 1 & 117 & 8.9 \\
\hline EA-O2959 & 29 & 18.7 & 43 & 6 & 65 & 2 & 22 & 6.8 \\
\hline EA-TPO & 41 & 43.1 & 40 & 3 & 112 & 4 & 55 & 9.6 \\
\hline EA-TPOL & 35 & 59.1 & 45 & 3 & 88 & 4 & 120 & 7.6 \\
\hline EA-O819 & 30 & 48.1 & 47 & 15 & 83 & 2 & 30 & 8.7 \\
\hline EA-O2022 & 37 & 84.4 & 60 & 6 & 92 & 0 & 108 & 8.9 \\
\hline EA-O2100 & 37 & 6.7 & 39 & 3 & 117 & 4 & 135 & 7.5 \\
\hline EA-O4265 & 45 & 38.5 & 50 & 3 & 91 & 2 & 150 & 7.2 \\
\hline
\end{tabular}

${ }^{(1)}$ maximum heat flow peak; ${ }^{(2)}$ maximum polymerization rate determined by RT-IR method; ${ }^{(3)}$ conversion determined by RT-IR method; -no curing. 
Both coatings prepared from epoxy and epoxy acrylate resins obtained in the cationic process achieve the shortest tack-free time with use of certain photoinitiators in the form of diaryliodonium cation ((7-methoxy-4-methylcoumarin-3-yl)phenyliodonium hexafluoroantimonate (7M-S) and (7-methoxy-4-methylcoumarin-3-yl)phenyliodonium hexafluorophosphate (7M-P)). Although these photoinitiators lead to the lowest conversions of epoxy groups among all tested systems and run slower, their shortest tack-free time can probably be attributed to absorption in the longer wavelength range $(350 \mathrm{~nm})$, which is responsible for the surface drying of the coatings. In turn, the longest tack-free time has coatings with other diarylyodonium cations, whose absorption characteristics are at shorter wavelengths, i.e., in the range of UV-C radiation. It is well known that UV-C radiation penetrates deep into the coatings; therefore, it is difficult to obtain surface dryness. Epoxyacrylate coatings achieved a lower degree of conversion, and to obtain tack-free time coatings, they were cured for a longer time than epoxy coatings. Interestingly, however, EA coatings have a higher hardness compared to epoxy resin coatings. Despite the lower number of epoxy groups, epoxy acrylate resins should produce coatings of lower hardness than epoxy resins. Their higher hardness can be attributed to longer curing time, which is associated with cross-linking the polymer and greater post-curing of the coatings. It turns out that the choice of photoinitiator affects the adhesion. The coatings with triarylsulfonium cations showed the best adhesion. This may be related to the achievement of a high degree of conversion of the epoxy groups. All coatings obtained in the cationic process had a high gloss, and the highest yellowness was found in diarylyodonium cations, in particular 7MS and 7MP.

In comparison to the cationic process, the radical process of curing epoxy acrylate formulations was characterized by a much shorter time-free time, and most coatings with radical photoinitiators achieve it within $3 \mathrm{~s}$ (while in the cationic process, this time was achieved after $33 \mathrm{~s}$ ). This is probably related to the much higher rate of radical polymerization compared to the cationic process. However, despite obtaining surface dryness in a short time, a higher photopolymerization rate, and much higher conversion of unsaturated bonds from acrylate groups, the coatings obtained in the radical process have lower hardness compared to those obtained in the cationic process. This effect may be related to the formation of flexible networks in the form of polymethacrylate backbone with pending epoxy groups, as opposed to the more rigid networks obtained by the cationic process, resulting in polyether-type polymer chains with pending unreacted acrylate groups. The stiffness of polyether networks may also result from the possibility of forming hydrogen bonds, which additionally stiffen the structure. It has also been shown that the selection of a radical photoinitiator affects the photopolymerization rate, conversion, tack-free time, and the properties of cured coatings, in particular, adhesion, gloss, and yellowness.

\section{Conclusions}

In this paper, an epoxy acrylate resin based on the industrial-grade bisphenol Abased epoxy resin and acrylic acid have been synthesized in order to develop hybrid resin comprising both epoxide group and reactive, terminal unsaturation. The significant advantage of this type of resin is the presence of two functional groups in one molecule, which can be used in the photopolymerization process and obtain coatings with a wide range of properties or used for subsequent modification. The obtained epoxy acrylate prepolymer was employed to formulate photocurable coating compositions containing, besides the EA binder, also cationic or radical photoinitiators. Owing to the presence of both epoxy and double carbon-carbon pendant groups, the reaction product exhibits photocrosslinking via two distinct mechanisms: (i) cationic ring-opening polymerization and (ii) free radical polymerization. The mechanism of photopolymerization, the type of the polymer network formed, and the selection of the photoinitiator have been shown to affect the kinetics of the process as well as the properties of the cured coatings. The cationic polymerization proceeds slower and leads to a lower degree of reaction compared 
to the radical process. As a result of this process, the surface dryness of the cured coatings is achieved in a longer time; however, the coatings have a higher hardness and gloss. It has also been shown that the kinetics of polymerization and the properties of cured coatings differ when using various types of photoinitiators. The properties of the coatings obtained by the cationic and radical processes may differ, among others, because they form different polymer networks. When cationic phtoinitiators were applied, polyether-type polymer chains with pending acrylate groups were formed. In the case of free radical polymerization, epoxy acrylates certainly formed a polyacrylate backbone with pending epoxy groups. The polyether-type polymers produce higher hardness coatings in relation to polyacrylates.

Author Contributions: Conceptualization, P.B.; methodology, P.B.; validation, P.B., K.M. and Z.C.; formal analysis, P.B.; investigation, P.B., K.M. and M.N.; data curation, P.B., K.M. and M.N.; writing-original draft preparation, P.B. and K.M.; writing—review and editing, Z.C.; supervision, P.B. and Z.C.; project administration, P.B.; funding acquisition, P.B. All authors have read and agreed to the published version of the manuscript.

Funding: This work was supported by The National Centre for Research and Development (NCBR) (Grant No. LIDER/16/0102/L-10/18/NCBR/2019).

Institutional Review Board Statement: Not applicable.

Informed Consent Statement: Not applicable.

Data Availability Statement: Not applicable.

Conflicts of Interest: The authors declare no conflict of interest.

\section{References}

1. Shen, L.; Li, Y.; Zheng, J.; Lu, M.; Wu, K. Modified epoxy acrylate resin for photocurable temporary protective coatings. Prog. Org. Coat. 2015, 89, 17-25. [CrossRef]

2. Gorsche, C.; Seidler, K.; Knaack, P.; Dorfinger, P.; Koch, T.; Stampfl, J.; Moszner, N.; Liska, R. Rapid formation of regulated methacrylate networks yielding tough materials for lithography-based 3D printing. Polym. Chem. 2016, 7, 2009-2014. [CrossRef]

3. Wang, K.; Wu, W.; Zhu, X.; Yu, Q. Synthesis and Photopolymerization of 2,2-Di((Acryloyloxy)Methyl)Butyl Bis(2(Acryloyloxy)Ethyl)Carbamate. Des. Monomers Polym. 2012, 15, 31-39. [CrossRef]

4. Decker, C. Kinetic Study and New Applications of UV Radiation Curing. Macromol. Rapid Commun. 2002, 23, 1067-1093. [CrossRef]

5. Gziut, K.; Kowalczyk, A. Influence of radical photoinitiators on features of polyacrylate syrups and self-adhesives. Polimery 2020, 65, 268-274. [CrossRef]

6. Sanai, Y.; Kubota, K. Effect of UV-curing conditions on the polymer structures: A comparison between coating and adhesive. Polym. J. 2020, 52, 1153-1163. [CrossRef]

7. Yagci, Y.; Jockusch, S.; Turro, N.J. Photoinitiated Polymerization: Advances, Challenges, and Opportunities. Macromolecules 2010, 43, 6245-6260. [CrossRef]

8. Sangermano, M. Advances in cationic photopolymerization. Pure Appl. Chem. 2012, 84, 2089-2101. [CrossRef]

9. Kabatc, J.; Jurek, K. Free radical formation in three-component photoinitiating systems. Polymer 2012, 53, 1973-1980. [CrossRef]

10. Rocco, C.; Karasu, F.; Croutxé-Barghorn, C.; Allonas, X.; Lecompère, M.; Riess, G.; Zhang, Y.; Esteves, A.; Van Der Ven, L.; Van Benthem, R.; et al. Highly-interpenetrated and phase-separated UV-cured interpenetrating methacrylate-epoxide polymer networks: Influence of the composition on properties and microstructure. Mater. Today Commun. 2016, 6, 17-27. [CrossRef]

11. Chen, Z.; Webster, D.C. Study of cationic UV curing and UV laser ablation behavior of coatings sensitized by novel sensitizers. Polymer 2006, 47, 3715-3726. [CrossRef]

12. Malik, M.S.; Schogl, S.; Wolfahrt, M.; Sangermano, M. Review on UV-induced cationic frontal polymerization of epoxy monomers. Polymer 2020, 12, 2146. [CrossRef]

13. Decker, C.; Viet, T.N.T.; Thi, H.P. Photoinitiated cationic polymerization of epoxides. Polym. Int. 2001, 50, 986-997. [CrossRef]

14. Škola, O.; Jašúrek, B.; Veselý, D.; Němec, P. Mechanical properties of polymer layers fabricated via hybrid free radical-cationic polymerization of acrylate, epoxide, and oxetane binders. Prog. Org. Coat. 2016, 101, 279-287. [CrossRef]

15. Sangermano, M.; Roppolo, I.; Chiappone, A. New Horizons in Cationic Photopolymerization. Polymers 2018, 10, 136. [CrossRef]

16. Nowak, D.; Ortyl, J.; Kamińska-Borek, I.; Kukuła, K.; Topa, M.; Popielarz, R. Photopolymerization of hybrid monomers: Part I: Comparison of the performance of selected photoinitiators in cationic and free-radical polymerization of hybrid monomers. Polym. Test. 2017, 64, 313-320. [CrossRef] 
17. Park, C.-H.; Lee, S.-W.; Park, J.-W.; Kim, H.-J. Preparation and characterization of dual curable adhesives containing epoxy and acrylate functionalities. React. Funct. Polym. 2013, 73, 641-646. [CrossRef]

18. Jaswal, S.; Gaur, B. New trends in vinyl ester resins. Rev. Chem. Eng. 2014, 30, 567-568. [CrossRef]

19. Liu, P.; Gu, A.; Liang, G.; Guan, Q.; Yuan, L. Preparation and properties of novel high performance UV-curable epoxy acrylate/hyperbranched polysiloxane coatings. Prog. Org. Coat. 2012, 74, 142-150. [CrossRef]

20. Asif, A.; Huang, C.; Shi, W. Structure?property study of waterborne, polyurethane acrylate dispersions based on hyperbranched aliphatic polyester for UV-curable coatings. Colloid Polym. Sci. 2004, 283, 200-208. [CrossRef]

21. Oprea, S.; Vlad, S.; Stanciu, A.; Macoveanu, M. Epoxy urethane acrylate. Eur. Polym. J. 2000, 36, 373-378. [CrossRef]

22. Tasic, S.; Bozic, B.; Dunjic, B. Synthesis of new hyperbranched urethane-acrylates and their evaluation in UV-curable coatings. Prog. Org. Coat. 2004, 51, 320-327. [CrossRef]

23. Bednarczyk, P.; Irska, I.; Gziut, K.; Ossowicz-Rupniewska, P. Novel Multifunctional Epoxy (Meth)Acrylate Resins and Coatings Preparation via Cationic and Free-Radical Photopolymerization. Polymers 2021, 13, 1718. [CrossRef] [PubMed]

24. Duran, H.; Meng, S.; Kim, N.; Hu, J.; Kyu, T.; Natarajan, L.V.; Tondiglia, V.P.; Bunning, T.J. Kinetics of photopolymerizationinduced phase separation and morphology development in mixtures of a nematic liquid crystal and multifunctional acrylate. Polymer 2008, 49, 534-545. [CrossRef]

25. Yin, B.; Zhang, J. A novel photocurable modified epoxy resin for high heat resistance coatings. Colloid Polym. Sci. 2020, 298, 1303-1312. [CrossRef]

26. Park, Y.-J.; Lim, D.-H.; Kim, H.-J.; Park, D.-S.; Sung, I.-K. UV- and thermal-curing behaviors of dual-curable adhesives based on epoxy acrylate oligomers. Int. J. Adhes. Adhes. 2009, 29, 710-717. [CrossRef]

27. Bajpai, M.; Shukla, V.; Kumar, A. Film performance and UV curing of epoxy acrylate resins. Prog. Org. Coat. 2002, 44, 271-278. [CrossRef]

28. Cho, C.H.; Son, I.; Yoo, J.Y.; Kim, J.H.; Lee, B.; Moon, G.; Lee, E.; Lee, J.H. New UV/heat dual-curable sealant containing acrylate-epoxy hybrid resin for highly adhesive liquid crystal device. Mol. Cryst. Liq. Cryst. 2019, 678, 84-90. [CrossRef]

29. Feng, Y.; Hu, J.; Wang, F.; Huang, Q.; Peng, C.; Xu, Z. Synthesizing promising epoxy acrylate prepolymers applied in ultraviolet cured adhesives based on esterification reaction. Mater. Res. Express 2018, 5, 065321. [CrossRef]

30. Bayramoğlu, G.; Kahraman, M.V.; Kayaman-Apohan, N.; Güngör, A. Synthesis and characterization of UV-curable dual hybrid oligomers based on epoxy acrylate containing pendant alkoxysilane groups. Prog. Org. Coat. 2006, 57, 50-55. [CrossRef]

31. Fischer, J.; Ritter, H. Oligomeric epoxide-amine adducts based on 2-amino-N-isopropylacetamide and $\alpha$-amino- $\varepsilon$-caprolactam: Solubility in presence of cyclodextrin and curing properties. Beilstein J. Org. Chem. 2013, 9, 2803-2811. [CrossRef] [PubMed]

32. Chowdhury, R.A.; Hosur, M.V.; Nuruddin, M.; Tcherbi-Narteh, A.; Kumar, A.; Boddu, V.; Jeelani, S. Self-healing epoxy composites: Preparation, characterization and healing performance. J. Mater. Res. Technol. 2015, 4, 33-43. [CrossRef]

33. Cabanelas, J.C.; Baselga, J. Applications of FTIR on Epoxy Resins-Identification, Monitoring the Curing Process, Phase Separation and Water Uptake. Infrared Spectrosc. Mater. Sci. Eng. Technol. 2012, 2012, 261-284. [CrossRef]

34. Asman, S.; Mohamad, S.; Sarih, N.M. Exploiting $\beta$-Cyclodextrin in Molecular Imprinting for Achieving Recognition of Benzylparaben in Aqueous Media. Int. J. Mol. Sci. 2015, 16, 3656-3676. [CrossRef]

35. Nurhayati, T.; Royani, I. Synthesis and characterization of MAA-based molecularly-imprinted polymer (MIP) with D-glucose template. J. Phys. Conf. Ser. 2016, 739, 12143. [CrossRef]

36. Arbain, N.H.; Salimon, J. Synthesis and Characterization of Ester Trimethylolpropane Based Jatropha Curcas Oil as Biolubricant Base Stocks. J. Sci. Technol. 2010, 2, 47-58.

37. Wu, Z.; Li, S.; Liu, M.; Wang, Z.; Liu, X. Liquid oxygen compatible epoxy resin: Modification and characterization. RSC Adv. 2015, 5, 11325-11333. [CrossRef] 